\title{
Behavioral economics of corruption and its implications
}

Economia comportamental da corrupção e suas implicações

ROBERTA MURAMATSU*

ANA MARIA A. F. BIANCHI**

\begin{abstract}
RESUMO: Este artigo sustenta que os modelos econômicos tradicionais de corrupção, baseados em otimização de custos e benefícios esperados, são insuficientes para compreender e enfrentar a desonestidade no mundo real. Embarca numa revisão da literatura para discutir os papéis exercidos por vieses cognitivos e preferências sociais nos desvios do comportamento honesto. Discute ainda as implicações da economia comportamental para o debate sobre como combater a corrupção e promover a integridade.

PALAVRAS-CHAVE: Economia comportamental, corrupção, metodologia, experimentos, política.
\end{abstract}

ABSTRACT: This paper holds that the standard economic accounts of corruption based on expected costs and benefits are insufficient to understand and to tackle dishonesty in the real world. It embarks on a survey of the literature to discuss the major roles automatic judgments and decisions, as well as cognitive biases and social preferences might play in deviations from honest behavior. The paper further discusses the implications of behavioral economics to the debate over how to fight corruption and foster integrity.

JEL CLASSIFICATION: B40; B41; D90; D91.

Keywords: Behavioral economics, corruption, methodology, experiments, policy

\section{INTRODUCTION}

The task of explaining corruption is a complex one. This is partly so because corruption refers to a multifaceted phenomenon transcending economic incentives,

\footnotetext{
* Adjunct Professor of Economics and Researcher of Mackenzie Center for Economic Freedom, Mackenzie Presbyterian University, São Paulo/SP, Brazil. E-mail: robertamuramatsu@gmail.com, roberta. muramatsu@mackenzie.br. Orcid: https://orcid.org/0000-0002-5286-6952.

** Full Professor of the School of Economics, Business and Accounting of the University of São Paulo - USP, São Paulo/SP, Brazil. E-mail: amafbian@usp.br. Orcid: https://orcid.org/0000-0002-4967-0764. Submitted: 24/October/2019; Approved: 14/May/2020.
} 
such as political factors, institutional signals, moral commitments, among many others (Rose-Ackerman and Palifka, 2016; Lambsdorff, 2015; Carvalho and Silva 2016; Silva, 1996). To complicate matters, the definition and measurement of corruption is often the target of criticism and questioning. Corrupt behavior involves quantitative as well as qualitative issues, which are difficult to isolate.

According to the United Nations, corruption, bribery, theft and tax evasion cost at least US\$ 1.26 trillion each year to developing countries (Transparency International, 2018). The results of the United Nations Convention Against Corruption (UNCAC) emphasize that every year billions of dollars spent in bribes, extortions and other forms of corruption could be better allocated to economically efficient activities and anti-poverty programs. As a result, corruption gives rise to distortions at the level of individuals, business activities and society (UNCAC, 2004).

Corruption constrains human quality of life, ruins careers and reputation; prevents low income individuals from access to basic services, deprives employment opportunities and violates fundamental rights, such as freedom and dignity. Corruption also has negative social effects, because it puts democracy and the rule of law under threat. It rewards the emergence of organized crime and terrorism, among other negative unintended consequences. Corruption undermines economic development, since it distorts market coordination, punishes savings and investments and promotes loss of confidence in government officials and formal institutions. It also damages business and economic environment of a country because it hurts the market process and constrains competition. As a result, corrupt behaviors constrain productive activities, increase the costs of doing business, and punish innovation.

Given the foregoing consequences of corruption, this paper shares the view that making sense of corruption requires us to embark on an interdisciplinary perspective that celebrates integration of distinct research fields like economics, law, political science and psychology (Dimant, 2013).

The starting point of our work is the conjecture that the standard approach to the study of corruption (which incorporates activities like exchange of favors, extortion, money laundering, tax evasion, electoral fraud, nepotism, bribes), drawing on rational choice maximization hypothesis, expected costs and benefits, and principal-agent models, simplifies too much. It cannot provide a richer understanding of some judgment and decision-making mechanisms that are relevant to the emergence and persistence of corrupt behaviors and deviations from private and public integrity. In addition, many conventional anticorruption policies tend to concentrate mainly on controls, punishment and deterrence, thus failing to deliver what they promise in terms of promoting integrity, trust, cooperation and efficiency gains (OECD, 2018).

In this paper, we draw on contributions from economic methodology to provide an interpretation of why corruption and integrity researchers have incorporat- 
ed behavioral economic insights and what implications such interdisciplinary move might carry (Hands, 2012).

Putting it another way, the current article engages in an extensive survey of the literature to investigate how economic explanations of corruption have evolved and why they seem to converge on behavioral accounts. Our hunch is that our narrative can help integrate evidence about shifting understandings of what lies at the heart of corrupt behavior and its enforcement mechanisms. It enables us to identify and assess new directions of empirical research and its implications for policy. The ineffectiveness of some public integrity programs or anti-corruption policies might have to do with the fragile psychological foundations of mainstream economic theory. We suggest that evidence-based anticorruption policies and public integrity programs might profit from cross fertilization with behavioral economic field experiments, that promises to offer new tools for identification, design, implementation and subsequent evaluation of development programs and policies (Datta and Mullanaithan, 2005).

A detailed account of these experiments is useful for their replication in different societies, cultures, and historical periods. As experiments are context-dependent, we claim that they should be replicated in different periods of time and settings, in order to get a better understanding of what factors are at play in each case.

We go on to claim that traditional economic accounts of corruption can be supplemented with behavioral factors. More precisely, we present and analyze the relevance of some cognitive heuristics and biases (loss aversion framing effect, ambiguity aversion and confirmation bias or overconfidence) and social preferences for the emergence and persistence of dishonesty and corruption among private as well as public agents. The current work also aims to take account of some of the implications of behavioral economics to the debate over how to fight corruption and promote integrity, understood as honesty and consistent adherence to strong moral and ethical principles and values.

In order to pursue the foregoing explanatory goals, the remainder of the paper is structured as follows. The first section briefly explains standard economic approach to corruption and goes on to suggest that it fails to provide a broad understanding of everyday cases of corruption and departures from public as well as private integrity, inspiring anticorruption measures that turn out to backfire. The second section presents some foundations of behavioral economics that are useful to develop less psychologically unrealistic accounts of corruption and dishonesty. It discusses how some Homo sapiens' cognitive heuristics and biases, as well as social preferences and the human tendency to reciprocate to cooperation, can help to explain actual corruption and dishonesty. The third section analyzes what implications behavioral economic studies of corruption carry for the debate over how to counter corruption and promote trust and integrity. Finally, it goes on to wrap the main points up and concludes. 


\section{THE CONVENTIONAL ECONOMIC APPROACH TO CORRUPTION AND ITS LIMITATIONS}

Despite the ambiguity that characterizes the concept of corruption, there is a long-standing tradition that regards corruption as a crime of calculation, not passion (Klitgaard, 1988, p. 4). According to such perspective, research on corruption is built on the assumption that individuals are "rational beings attempting to further their self-interest in a world of scarce resources" (Rose- Ackerman, 1978, p. 5).

The foregoing economic portrait of corrupt behavior is largely inspired by Gary Becker's famous 1968 paper entitled "Crime and Punishment”, which assumes that the decision of whether utility maximizing agents will embark on a pattern of criminal behavior will depend on the incentive structure of their environment. Putting somewhat differently, criminal behavior is explained in terms of conscious judgments about expected costs and benefits associated with the decision task (Garoupa, 2014). If this is so, there will be no crime if expected marginal costs are larger than gains. Becker's account of corruption can be reframed by the following equation:

(1) $\mathrm{EU}=\mathrm{p} U(\mathrm{~b}-\mathrm{f})+(1-\mathrm{p}) \mathrm{U}(\mathrm{b})$, where

$\mathrm{EU}$ is the expected utility, p corresponds to the probability of being detected and punished, $b$ is the gain if there no crime detection, whereas (b-f) amounts to the net gain when crime is discovered. All costs and gains are accommodated in the model and reducible to monetary values (ibid.). Note that equation (1) implies that criminal behavior involves judgment and decision under risk. Corruption might emerge even among risk-averse individuals if its gains are large, while the probability of being caught and severity of punishment are small.

Becker's economic explanation of crime became the paradigmatic approach to corrupt behavior. Later economists interested in corruption at the interface of the public and private sectors went on to study corrupt behaviors based on the principal-agent agency model (Dimant, 2013).

The principal-agent framework is built on the conditions below:

C1. There is an individual or group called the Principal that delegates his decision power to another part dubbed the Agent, who is to represent the first actor's aims.

C2. Due to asymmetric information and the principal's incapacity of dealing with the knowledge problem, the agent makes strategic use of the power and trust given to him to achieve his own interests or a potential client's goals.

Conditions (C1) and (C2) shed light on the incentives the agent might have for opportunistic behavior, in tune with the definition of corruption as abuse of entrusted power to pursue private gains. In such framework, the agent tends to deviate from rules and contracts that structure the exchange relationship with the prin- 
cipal. Rule violations occur because the agent can have higher gains from a cooperative relationship with a corruptor that pays a bribe in return of privileges or profits, through their personal or political connections (for instance, confidential information).

Note that corruption within the above economic framework implies a deviation from contractual relations (exchange relationship) between the principal (the electorate, for example) and the agent (a public official), promoted by a third party (corruptor) (Vannucci, 2015; Della Porta and Vannucci, 2012). Just like Becker's model, in the agency model programs or measures to fight corruption are based on rewards and punishments.

As a result, the conventional economic approach will recommend anticorruption policies that involve strong controls, increased levels of monitoring, severe punishment devices and credible enforcement mechanisms, targeted at individuals with high discretionary decision-making powers at the public as well as private spheres (Rose-Ackerman and Palifka, 2016). However, excessive control can backfire and undermine intrinsic motivation for behaving in an ethical manner.

Schulze and Frank (2003) designed an experiment to test the effectiveness of control on corrupt behavior. Before watching a movie at the university club (that played the role of the principal), subjects (that played the role of the agent) were requested to decide on behalf of a movie club that had to deal with the following task: a 200 DM (approximately 102 euros) bill fell into a pipe and could not be removed without the technical support of a plumbing company. The experiment considered 10 different plumbing companies, which charged different prices for retrieving the money. According to the experimental design, there were two types of offers: one that corresponded to the price of the plumbing service for which the club had to pay; another was a bribe the plumbing company was ready to pay for the agent to opt for its service. Each participant was asked to fill a form of a sheet with his or her decision over the company. After the movie, sheets were randomly drawn and payments made to the lucky agent who would receive the amount of 200 DM minus the payment of the successful company. The experiment had two different treatments - one without risk of detection of corruption (non-risk treatment) and the second one involving a certain risk of detection (risk treatment). If the bribe was unnoticed, the participant would receive the sum of money according to his/her decision. If, however, the dishonest behavior was detected, the agent would make no money and the cheapest company would have the service. The findings are very interesting: bribes were higher when control occurs (91.4 DM under risk treatment) than in the context without control (87.9 under non-risk). In the non-risk treatment, $9.4 \%$ of the 160 participants were honest, as compared to only $0.9 \%$ of the 230 participants in the monitoring treatment. For bribes up to $32 \mathrm{DM}$, the share of honest people was $19.4 \%$ in the non-risk treatment and only $4.8 \%$ in the treatment where corruption detection was a possibility.

The foregoing results challenge the view that deterrence promotes honesty and prevents people from behaving in a corrupt way. Rather, increase of controls and levels of monitoring can undermine the intrinsic motivation for behaving honestly. 
The above findings carry interesting policy implications - focusing on deterrence and enforcement mechanisms might not suffice to fight corruption. Quite the opposite: in the case of the experiment of Schulze and Frank (2003, p. 158), surveillance increased overall corruptibility.

No doubt that economic studies make an important point when they highlight that one way of making corruption less rewarding is by increasing detection probability. However, the literature on behavioral sciences identifies an unintended undesirable consequence of controlling and constraining individual decision power, which is the fact that their intrinsic motivation for integrity can be severely hurt.

Promoting transparency and information disclosure is often another standard measure to fight corruption that draws on conventional economic accounts of corruption. As a matter of fact, transparency shapes incentives for weighing net expected gains from dishonest behavior. Yet there are also cases in which transparency is a necessary but an insufficient constraint on dishonest and corrupt behaviors.

To complicate matters, the very task of disclosing potential conflicts of interest can be followed by unintended consequences, such as moral licensing and rationalization mechanisms to justify deviations from social (ethical) norms. George Loewenstein, Dayllian Cain and Sunita Sah report some experiments suggesting that information disclosure of information can backfire (Loewenstein et al., 2011; Loewenstein et al., 2012). In a series of studies that simulate physician-doctor relationships, they found out that disclosed information about doctors' potential conflicting interests between their personal interests and professional responsibilities can lead them to make even more biased recommendations or advices. This is due to the activation of two psychological mechanisms that help advisors (physicians, among other professionals) justify the pursuit of their own interests, such as payments received from pharmaceutical companies or medical device firms at the expense of their advisees' best options. One mechanism is the professional's tendency to exaggerate the advice as a strategy to signal to people advised that information disclosed reflects that conflicts are manageable. This first mechanism is called strategic exaggeration, and serves to anticipate advisee's reaction to information about the advisor's personal interests. A second mechanism is rationalization for undermining advisor's professional responsibilities, called moral licensing: since information is disclosed and available to those advised, the professional feels entitled to favor what is best for him/herself. In addition, there is evidence suggesting that disclosing physicians' financial incentives to patients often lead patients to regard doctors paid by pharmaceutical firms as experts deserving extra remuneration and trust (Hampson et al., 2006).

All this suggests that transparency and information disclosure need not be taken as panacea. Research on corruption might profit from digging deeper into the complex ways in which individuals make judgments and decisions in the real world, which can be accomplished with the help of some powerful insights from behavioral economics. 


\section{BEHAVIORAL ECONOMICS APPLICATIONS}

\section{TO RESEARCH ON CORRUPTION}

Behavioral economics promises to change the face of standard financial economics, health economics, environmental economics, development economics, among others (Camerer, Loewenstein and Rabin, 2003; Diamond and Vartiainen 2007; DellaVigna, 2009). In addition, behavioral economics aims to contribute to the debate over agent-based public policy and regulation that help individuals better coordinate their own intentions and actions (Thaler and Sunstein, 2003; Thaler and Sunstein 2009, Sunstein 2012). Such theoretical and empirical developments also open new grounds for the research on corruption and in law and economics (Sunstein, 2000; Lambsdorff ,2012; Zamir and Teichman, 2018; Zúñiga, 2018).

The foregoing behavioral economic applications is built on Daniel Kahneman's map of bounded rationality, consisting in two modes of thinking and decision-making (Kahneman, 2003). The so-called System 1 refers to automatic judgment and decision-making that are triggered by cue-based mental shortcuts or heuristics under context-specific situations, simplifying matters and thus enabling individuals to react fast to cognitively demanding tasks. System 2 in turn amounts to effortful, deliberate, controlled thinking mechanisms that appeal to logic and/or high order cognition to deal with to problem-solving tasks.

One implication of the automatic system is that behavior is sensitive to how decision problems and choice alternatives are perceived (in terms of relative losses or gain, for instance). In addition, System 1 highlights that actual behavior can be driven by intuitions, emotions and social norms that frame boundedly rational individuals but are not necessarily in tune with their best available options and interests (Tversky and Kahneman, 1974; Kahneman, 2003).

This paper claims that the increasing interest in behavioral economic applications to corruption is a response to researchers' acknowledgement that the standard economic approach fails to uncover how mechanisms related to incentives, automatic thinking and social preferences work together, under particular contexts (Lambsdorff, 2012; Vannucci, 2015). To put it somehow differently, the behavioral turn to research on integrity and corruption seems to result from the search for new tools, based on the view that corruption is not reducible to a crime of calculation and insensitive to reciprocity norms or conventions and perceived emotionladen contexts. In what follows, we will briefly present and analyze how heuristics, biases and the human tendency to reciprocate cooperation have a direct influence on dishonesty and integrity. To us, a clearer understanding of the foregoing explanatory items is important to rethink some regulatory measures and policies to fight corruption in the real world of boundedly rational agents.

\section{The connections between corruption and loss aversion}

In their famous 1981 article "The Framing of Decisions and the Psychology of Choice", Kahneman and Tversky highlight that human perception is imperfect and 
context-dependent. Therefore individual choices are responsive to how choice options are perceived (i.e., how they are mentally represented) rather than to the alternatives themselves. As a result, decision-making depends on whether they are regarded in terms of relative losses or gains. In order to test whether variations of frame influence the outcomes of individual choices, the authors designed an experiment based on the following two decision tasks, the first one involving gains (lives that would be saved) and the second one involving losses (people who would die).

It is important to stress that in the two problems both decision tasks were identical in terms of prospects. However, participants reacted differently. Kahneman and Tversky found out that $72 \%$ (out of 152 participants) preferred alternative A (sure gain) over option B (a lottery) in the first decision problem, framed in terms of gains. When alternatives were framed in a loss context, as in the second problem, $78 \%$ (out of 155 participants) prefer method D (a lottery) over option C (a sure loss).

Such outcomes shed some light on the fact that human perceive losses and gains asymmetrically. This is because they tend to favor a sure outcome when they face a gain context, whereas they favor a risky option in a loss frame, implying that individuals have loss aversion and losses loom larger than gains. Given our purposes, the interesting question is to examine whether (and how) framing effects might influence ethical choices and reward dishonest behavior, such as lying, for example.

According to Mary Kern and Dolly Chugh (2009), unethical behavior can be triggered by automatic judgment and decision-making mechanisms. They go on to suggest that dishonest choices are more likely to occur when individuals perceive themselves in loss context rather than gain. Based on previous studies that connect loss frames with unethical behavior, the authors run one scenario-experiment with monetary gain described to the 55 participants as follows:

You are an entrepreneur interested in acquiring a business that is currently owned by a competitor. The competitor, however, has not shown any interest in either selling his business or merging with your company. To gain inside knowledge of his firm, you consider hiring a consultant you know to call contacts in your competitor's business and ask if the company is having any serious problems that might threaten its viability. If there are such problems, you might be able to use the information to either hire away the company's employees or get the competitor to sell. As of now, your analysis suggests that you have a $25 \%$ chance of gaining $/ 75 \%$ chance of losing the acquisition. How likely are you to hire this consultant $(1=$ very unlikely, $7=$ very likely $)$ ?

(Source: Kern and Chugh, 2009, p. 379)

The results suggest that the designed loss frame led more participants to accept hiring a consultant (which means getting inside information, regarded as something unethical) than subjects that faced a gain frame. The authors concluded that 
under the perceived domain of losses individuals automatically react by adjusting their ethical preferences.

Kern and Chugh also run a second experiment, in which MBA students had to negotiate the sales of a family property. Randomly assigned subjects, playing the role of the seller's agent, were informed that the family wanted to sell only to a person that would make a "tasteful" use of the property. Other participants, who played the role of the buyer's agent, could not reveal the buyer's identity and neither his/her intentions. The experiment was designed to test whether a loss frame could influence the buyer's agent to make false promises and to behave unethically. The context was presented in a way that the agent would have a commission based on the negotiated sales price of the property. The buyer's agent was informed that she or he had $1 / 4$ probability of gaining the deal and $3 / 4$ of losing the family building (and therefore no commission). Based on four different measures of dishonesty and unethical behavior, Chern and Chugh found that in a loss context the buyer was more dishonest, lied more about their clients ideas about what to do with the family building, used more misrepresentation negotiation strategies, and even made more false promises than the buyer in a gain frame.

\section{Difficulties with identifying conflicts of interest and ambiguity might reward corruption}

By following Kahneman's model of bounded rationality in terms of fast and slow thinking, Yuval Feldman and Eliran Halali (2017) attempt to investigate the role automatic processes play in behaviors that deviate from individual professional or public integrity. The authors claim that there are many circumstances where ordinary people's self-interest can conflict with their professional or public integrity. Some examples can be found in medical or government decisions in which individual's pursuit of their own interests opposes their professional sense of duty. To Feldman and Halali, conflicts of interest are what lies at the heart of most unethical behaviors, both in public and corporate sectors. They go on to claim that the ambiguity underlying conflict of interest situations triggers automatic judgments and decisions towards individuals' "moral blind spots" and behaviors revealing their abuse of public position to obtain personal benefits. One example could be the case of an employer of a public regulatory agency, who was very generous to a regulated utility company because he visualized a future job opportunity in the private sector after his or her retirement.

In order to examine more carefully their conjecture, Feldman and Halali designed an online experiment that requested 99 participants from the online labor market to make an objective evaluation of the need to help and fund Edmond Safra Research Center. Participants were asked to read a paragraph describing this center and were informed about a conflict of interest. Subjects' task was to answer an 18 -item questionnaire that would allow for an objective assessment based on the type of research made by the center and on the evaluation of the researchers who were working there. Next they had to answer four binominal questions assessing 
subjects' agreement with a few statements and their "willingness to pay" for research financial support. Finally, participants also answered three yes/no questions to identify their sense of objectivity toward the Safra Center.

Before answering the 18 topics questionnaire, the experimenters framed participants' mindsets. For the automatic thinking condition, participants were requested to appeal to their intuitions to make their evaluation. In the analytical or controlled condition, participants were asked to write justifications for their answers to make sure about their careful reasoning. Moreover, experimenters created a context of conflict of interest, by telling participants that if their answers to the questionnaire revealed some interest in the research done at the Safra Center, they could be selected for a new questionnaire that would allow them to get a higher payment. In the 18-item questionnaire there were items with statements about the research done in the center, such as "Research conducted by this center is more important than most other research I'm familiar with in the social sciences." There were also statements about researchers, such as "the salaries of scientists at this center should be higher than other scientists' salaries". Subjects had to answer based on a scale of 1 (strongly disagree) to 6 (strongly agree).

Next participants had to respond to the following three statements: (i) "Research conducted by the Safra Center is crucial for the well-being of society," (ii) "The Safra Center's research will change the way we look at public institutions," and (iii) "The Safra Center's mission is the first attempt ever to deal with one of our most important problems." The answers required subjects to decide if the statements were accurate, if they agreed with them, if they would make them to a potential financial supporter, and if they were willing to sign a petition. Finally, participants were asked to answer three yes-no questions stating whether they were completely objective in their answers (Feldman and Halali, 2017, p. 11-13).

The results highlight that the participants' mean assessment of the Safra Center was better, in all experimental conditions, than the assessment made by researchers who actually worked for it. The mean assessment under the intuitive thinking condition was higher than evaluations made under the analytic context. Subjects were also more supportive of the Safra Center under the intuitive/automatic situation. This led the authors to suggest that ambiguity and intuitive thinking have a role in dishonest behavior even when individuals still regard themselves as professionals committed to ethical values. In some contexts, individuals' moral preferences are adjusted in a self-serving way.

\section{Confirmation bias and overconfidence blur human reasoning and favor dishonesty}

As we have discussed, automatic judgments and decisions play a role in explaining some instances of ethical misconduct and corruption. Based on the literature of behavioral ethics, Yuval Feldman (2018) draws attention to the fact that people underestimate their constrained ability to identify the moral aspects of their own thinking and choices. Individuals tend to process information in ways that are 
tuned to their preexisting beliefs, and often deceive themselves to find justifications for dishonest actions (Shalvi, Gino, Barkan and Ayal, 2015). Such automatic psychological mechanisms might prevent agents from recognizing their wrongful behavior when situations allow them to view themselves as "good" people (Feldman 2017, p. 88).

To complicate matters, individuals tend to think that their high professional competence is a necessary as well as a sufficient condition for avoiding suboptimal judgments and decisions. For instance, a very famous oncologist, well-known for his strong commitment to patients' well-being and precise clinical choices, might underestimate the fact that his/her drug prescriptions can be influenced by a pharmaceutical company that often sponsors his/her conferences and research team.

Feldman, Gauthier and Schuler (2013) discuss the case of Celecoxib Long-term Arthritis Safety Study trial, which attempted to investigate the effects of the pain medication Celecoxib on patients, during a certain time period. The authors criticize the fact that the published results of the medication only used data for six months. Researchers identified that after a semester using Celecoxib patients had fewer gastrointestinal complications than patients who used other medication. However, after one year, there was no gastrointestinal benefit associated with the use of Celecoxib relative to other medication. Reporting the data for only six months provided a biased account of Celecoxib's benefits. Besides, the report violated a second clause of the research protocol, which predicated that minor gastrointestinal complications should be distinguished from complications that resulted in patients being hospitalized. The new drug trial results suggested that patients who took Celecoxib had fewer complications but did not explicitly refer to serious gastrointestinal risks. In these circumstances it looks as if, while claiming to provide the market a new drug that could in principle help many people, medical researchers turned out to behave in a dishonest way.

Quite relatedly to the confirmation bias is the individual tendency to believe that one is more virtuous than one truly is. Such overconfidence is likely to enable the person to overlook his or her own (and some others') moral lapses, overrating their confidence on their own integrity (Nohria, 2015).

In an interesting article published in the New York Times, Max Bazerman and Ann Tenbrunsel (2011) state that people have difficulty with noticing a morally questionable component in their actions and behavior. According to the authors, the overconfidence bias often leads individuals to invoke an external constraint or reason to explain their conduct, instead of acknowledging a preference for a corrupt or dishonest option. This happens because people's judgments of appropriateness are cue-dependent, allowing individuals to distort their self-image to justify their behavior. For instance, individuals who have a lot of power, deal with time pressure and concentrate on broad political or organizational goals may fail to notice that their confidence prevents them to realize that some of their behaviors reveal ethical fading.

In a study with MBA students Bazerman and Tenbrunsel asked the participants to play the role of manufacturers in an industry that had been criticized by the en- 
vironmentalists due to the emission of a toxic gas. Subjects were randomly assigned to two different groups, where they would have to decide whether to break (or not) an agreement that would limit toxic emissions. In the first group, which participants were informed that they would be subject to financial sanctions, members were unable to identify the ethical component of their decision to break the agreement. This is partly so because participants were led to regard their decision as a purely financial choice. Interestingly enough, there was more adherence to the agreement among the participants of the second group, who were told that they would not face financial sanctions of any kind. In this group, participants were led to regard their decision problem as an ethical dilemma.

\section{Social preferences, reciprocity and the collaborative nature of corruption}

Although our tendency to cooperate with cooperators and to cheat cheaters can bring about positive individual as well as group outcomes, there are also some patterns of behavior that evolve in a maladaptive manner due to this behavioral trait (Fehr and Gachter, 2000). One example is corruption, which largely persists because of its collaborative roots (Lambsdorff, 2012).

Few would challenge the view that corruption deals are surrounded by uncertainty and that their survival depends on enforcement mechanisms that refer to reciprocity, trust and even gratitude. In an interesting paper, Lambsdorff and Frank (2011) run an experiment based on a version of an ultimatum game in which a businessperson representing a company (Firm Alpha), offering a low-quality service, gives a bribe to a government employee in order to gain a contract. This situation enables the civil servant to consider the following three alternatives: (a) report the bribery to higher authorities (via whistleblowing, for instance) and make civil servant be out of the game with no gain at all; (b) behave opportunistically in a way that maximizes his/her own material payoffs by accepting the bribe, yet not choosing Alpha, in which case the business person will feel cheated and regard the option as unfair and greedy; and (c) cooperate with the businessperson who cooperated with him/her.

The experimental findings suggest that men playing the role of a businessperson revealed stronger positive reciprocity (they cooperate with cooperators) and negative cooperation (they cheat cheaters even at a personal material cost) than women. Only $25 \%$ of businesswomen followed a positive reciprocity strategy. Rather, $65 \%$ women behaved opportunistically because they received the bribe and did not favor the businessperson who represented Firm Alpha.

The lesson to be drawn here is that individuals' tendency to reciprocate might somehow pose an extra challenge for fighting corruption. Dishonest deals carry collaborative roots and credible contract enforcement mechanisms. Perhaps the institutional device of plea bargaining can provide external incentives for individuals to deviate from positive reciprocity forces underlying corrupt practices. Therefore, plea bargain can be regarded as an alternative to identify and punish 
corrupted civil servants and private agents, by disentangling a network of systemic corruption that persists due to its collaborative nature (Hollander-Blumoff, 2007).

Furthermore, "corruption corrupts" to the extent that people who live in an institutional environment that rewards deviations from ethical norms and public integrity conventions feel licensed to act unethically whenever their moral and prosocial preferences do not fit well with their perceived self-image and/or group identity (Gächter and Schulz, 2016).

\section{FINAL REMARKS: IMPLICATIONS FOR POLICY AND CONCLUSIONS}

This paper provided an interpretation of the "psychologizing trend" in economic accounts of corruption. Inspired by a view of economic methodology as a research line that investigates the actual practice of economics and how it evolves over time, we claimed that contemporary research on corruption has shifted from its tight focus on cost-benefit analysis and the principal-agent model to new interdisciplinary and multidisciplinary endeavors. Since there is evidence of the major influence that behavioral factors have in triggering dishonest and corrupt practices, traditional accounts of corruption should be supplemented with insights offered by behavioral economics and correlated fields of investigation.

Such developments derive from economists' acknowledgment that corruption is a quite complex phenomenon. Many cognitive, emotional, social and cultural factors lie at its heart, which makes it difficult to come up with an uncontroversial simple definition and metric of corrupt actions. In response to the existing obstacles to isolate all the driving forces behind corruption and to recommend more effective policies, economists, psychologists, sociologists and others decided to explore the mutual gains from intellectual trade and to share empirical research skills. To us, this partly explains why policy makers become interested in economic experiments (randomized controlled trials, among others), which are applicable to a wide range of areas, such as education, health, environment, and public integrity.

The foregoing sections presented and analyzed in detail some behavioral economics applications to corruption research that shed extra light on how automatic and social mechanisms trigger judgments and decision-making. There is strong evidence that dishonest practices are more likely to occur when individuals perceive themselves in loss context rather than gain. Another possible source of corrupt behavior is overconfidence, which may drive highly reputed professionals to fail to notice the influence of self-interest in their daily practices.

Conflict of interests, intuitive thinking and ambiguity may also provide a fertile soil for corruption, since in many circumstances ordinary people's self-interest may conflict with their professional integrity. In these contexts, full disclosure of information can backfire, leading the individual to feel entitled to act in a self-serving way. The available experimental evidence shows that transparency, control mechanisms and very strict anticorruption laws carry the risk of harming intrinsic motives for the individual pursuit of his/her private and public integrity. There is 
evidence that severe controls put on civil servants or private executives bring negative unintended negative consequences. People react spitefully and find creative ways to violate "checks and balances" devices and compliance programs.

If this is so, the first implication of behavioral economics experiments for anticorruption policy is that policy makers should be very careful about the design and implementation of programs that concentrate on extrinsic motivations. These policies pose a high risk of crowding out internal motives for public integrity and honesty. As said, the strong focus on deterrence and material punishment can give reasons for moral licensing and cheating.

We therefore suggest that the proponents of integrity programs and anticorruption policies should pay closer attention to proposals to reframe decision tasks or choice architectures that inform people about the high payoffs of promoting integrity, trust and honesty over time. To us, subtle institutional changes and behavioral interventions are useful to increase individuals' awareness of what is at stake and his/hers own sense of responsibility. One way to achieve this goal is to make clear to individuals what they are ultimately prone to lose with corrupt deals, as well as how important is their social capital to lower transaction costs.

Reframing choice frames in a way that rejecting bribery and corrupt deals is taken as a foregone gain, rather than a loss, might require institutional reforms that remove ambiguity and complexity of contracts within the public and private domains. Very obscure interactions and excessive bureaucracy tend to punish (rather than reward) a self-binding commitment to high standards of integrity and professionalism.

Field experiments can provide means whereby policy makers will be able to identify features of the cultural environment (cronyism and reciprocity mechanisms, for instance) that somehow explain systemic corruption. Uncovering such items will help them to design and implement public integrity programs that promote ethical commitments and social values aligned with the pursuit of trust and honesty.

It is therefore vital to foster research on the social mechanisms that typify corruption and dishonest behavior. Despite the visible advances in behavioral economic experiments, further research is necessary given the multidimensionality of corruption. Much has been found, much more has yet to be investigated. As path-breaking as it may be, experimental research is no magic. It often relies on asking the participants to think about hypothetical situations in which they have to face decisions that may imply dishonest practices. Not many imply real life situations and, when they do, the amount of monetary reward involved is necessarily limited. Additionally, moral behavior is fundamentally context-dependent, and more research is needed to detect how people respond to stimuli in different cultural and economic settings. Brazil, among other societies, severely demands a thorough investigation of what causes corrupt behavior and how it takes place and disseminates.

It is important to stress that there are not yet much experimental evidence about how exactly behavioral economic insights can influence behaviors that counter actual world corruption (Zúñiga, 2018). Our hunch is that the experimental 
methodology is necessary though insufficient to deal with all the multiple facets of corruption in the real world. Isolating behavioral factors in the controlled environment of an experiment is a powerful strategy to investigate proximate causes of corrupt behaviors and dishonesty. However, complex historical, cultural and institutional factors cannot be easily controlled in an experiment. Again, to complicate matters, lab experimental evidence carries the risk of representing something different from the world outside. In reaction to that field experiments are supposed to better approach reality and essential dimensions of corrupt interactions that emerge and persist.

All the above complications justify the view that the issue of corruption cannot be addressed in isolation, but in the context of inter or multidisciplinary economic analysis. Analyzing the available evidence and further advancing this kind of empirical investigation is indispensable for the design and implementation of effective public policies.

\section{REFERENCES}

Ariely, Dan (2012) The honest truth about dishonesty. Harper Perennial.

Bazerman Max and Tenbrunsel, Ann E. (2011) “Stumbling into Bad Behavior”. New York Times, April $20^{\text {th }}, 2011$

Bazerman, Max H., and Tenbrunsel, Ann E. (2011) Blind Spots: Why We Fail to Do What's Right and What to Do about It. Princeton, N.J: Princeton University Press

Camerer, Colin F.; Loewenstein, G.; and Rabin, Matthew (2003) Advances in Behavioral Economics. Russel Sage Foundation.

Carvalho, Hamilton C.; Silva, Marcos Fernandes Gonçalves da (2016) "Economia Política da Corrupção: Os Gestores Públicos e as Questões Éticas”. Economia Política da Corrupção: Os Gestores Públicos e as Questões Éticas. 1ed.São Paulo: Egap - Editora Oficial do estado de São Paulo Escola de Gestão Pública, 2016, v. 1, p. 313-331.

Datta, Saugato and Mullanaithan, Sendhil (2014) "Behavioral Design: A New Approach to Development Policy". Review of Income and Wealth 60(1), March 2014, pp.7-35

Della Porta, Donnatella and Vannucci, Alberto (2012). Donnatella Della Porta and Alberto Vannucci. The Hidden Order of Corruption: An institutional approach. Ashgate.

Della Porta, Donnatella and Vannucci, Alberto (2014) Centripetal versus centrifugal corruption: A framework for the analysis of corrupt exchange and hidden governance structures. European University Institute.

DellaVigna, Stefano (2009) "Psychology and Economics: Evidence from the Field". Journal of Economic Literature 47(2): 315-372.

Diamond, Peter and Vartianen, Hannu (2007). Behavioral Economics and Its Applications. Princeton University Press.

Dimant, Eugene (2013) The nature of corruption: An interdisciplinary perspective. Economics. Discussion paper \# 2012-59.

Fehr, Ernst and Gachter, Simon (2000). "Cooperation and Punishment in Public Goods Experiments”. American Economic Review 90 (4): 980-994.

Feldman, Yuval (2017) "Using Behavioral Ethics to Curb Corruption”. Behavioral Science and Policy 3 (2), pp.88-99

Feldman, Yuval (2018) The law of good people - Challenging States'ability to regulate human behavior. Cambridge University press. 
Feldman, Yuval and Halali, Eliran (2019). Regulating "good” people in subtle conflicts of interest situations. Journal of Business Ethics, 154 (1).

Feldman, Yuval; Gauthier, Rebecca and Schuler, Troy (2013) " Curbing Misconduct in the Pharmaceutical Industry: Insights from Behavioral Ethics and the Behavioral Approach to Law". American Journal of Law and Medicine, 14 (3).

Gachter, Simon and Schultz, Jonathan (2016) "Intrinsic honesty and the prevalence of rule violations across societies". Nature 531: 496-499.

Garoupa, Nuno (2014) "Economic theory of criminal behavior". In: G. Bruinsma and D. Weisburd (eds). Encyclopedia of Criminology and Criminal Justice. Springer, New York, NY.

Hampson, Lindsay A. (2006) Patients' views on financial conflicts of interest in cancer research trials. The New England Journal of Medicine 355:2330-2337.

Hands, Wade (2012) "Normative rational choice theory: past, present, and future", Voprosy Economiki N.P. Redaktsiya zhurnala "Voprosy Economiki” 10.

Holander-Blumoff, Rebecca E. (2007) “Social Psychology, Information-Processing and Plea Bargaining”. Marquette Law Review, 91:163-182

Kahneman, Daniel and Tversky, Amos (1981) "The framin0g of decisions and the psychology of choice”. Science 211 (4481): 453-458.

Kahneman, Daniel (2003) “Maps of bounded rationality: psychology for behavioral economics”. American Economic Review, 93 (5): 1449-1475.

Kern, Mary and Chugh, Dolly (2009) “Bounded ethicality: the perils of loss framing”. Psychological Science 20 (3): 373-384.

Klitgaard, Robert (1988) Controlling Corruption. University of California Press, 230 p.

Lambsdorff, Johann Graf (2012) "Behavioral and experimental economics as a guidance to anticorruption”. in: D. Serra and L. Wantchecon (eds), New advances in experimental research on corruption (Research in Experimental Economics 15), Emerald Group, Bingley, pp. 279-300.

Lambsdorff, Johann G. and Frank, Björn (2011) “Corrupt reciprocity - Experimental evidence on a men's game". International Review of Law and Economics, 2011, 31 (2):116-125

Lambsdorff, Johann G. (2015) "Preventing corruption by promoting trust: insights from behavioral science”, Passauer Diskussionspapiere - Volkswirtschaftliche Reihe, 69(15), Universität Passau, Wirtschaftswissenschaftliche Fakultät, Passau.

Loewenstein, George; Sah, Sunita and Caine, Dayllian (2011) "The limits of transparency: pitfalls and potential of disclosing conflicts of interest". American Economic Review: Papers and Proceedings 2011, 101:3, 423-428.

Loewenstein, George; Sah, Sunita and Caine, Daylian (2012) The unintended consequences of conflict of interest disclosure. Viewpoint. Carnegie Mellon University.

OECD (2018) "Behavioural Insights For Public Integrity: Harnessing The Human Factor To Counter Corruption”, OECD Public Governance Reviews, Paris: OECD Publishing

Pearson, Steven D.; Kleinman, Ken and Rusimak, Donna (2006) “A Trial of Disclosing Physicians' Financial Incentives to Patients”. Archives of Internal Medicine, 166: 223-228

Rose-Ackerman, Susan-Rose; Palifka, Bonnie J. (2016) Corruption and Government: Causes, Consequences, and Reform. Cambridge University Press, 618 pp.

Schulze, Günther and Frank, Björn (2003) "Deterrence versus intrinsic motivation: experimental evidence on the determinants of corruptibility". Economics and Governance 4 (2): 143-160.

Shalvi, Shaul; Gino Francesca; Barkan Rachel and Ayal, Shahar (2015) "Self-Serving Justifications: Doing Wrong and Feeling Moral”. Psychological Science, 24 (2): 125-130.

Silva, Marcos Fernandes Gonçalves da (1996) Economia Política da Corrupção: o escândalo do orçamento”. EAESP/FGV/NPP - Núcleo De Pesquisas E Publicações. RELATÓRIO DE PESQUISA N ${ }^{\circ}$ 3/1995, 1996.

Sunstein, Cass R. (2013) “The Storrs lectures: behavioral economics and paternalism”. Yale Law Journal, vol. 122, issue 7, 2013. Available at: https://digitalcommons.law.yale.edu/ylj/vol122/iss7/3; internet 
Thaler, Richard H. and Sunstein, Cass R. (2003) Libertarian paternalism. American Economic Review 93 (2): $175-179$

Thaler, Richard H. and Sunstein, Cass R. (2009) Nudge: Improving decisions about health, wealth, and happiness. Yale University Press.

Transparency International (2019) Corruption Perceptions Index 2018.

Tversky, Amos and Kahneman, Daniel (1974) Amos Tversky and Daniel Kahneman, "Judgment under uncertainty: heuristics and biases”. Science 185 (4157): 1124-1131.

UNCAC (2004). United Nations Convention Against Corruption. New York, United Nations

Vannucci, Alberto (2015) "Three paradigms for the analysis of corruption". Labour and Law Issvannuccues 2 (1)

Vannucci, Alberto (2017) "Challenges in the Study of Corruption: approaches and policy implications", Revista Brasileira de Direito, Passo Fundo, vol.13, 1:251-281

Zamir, Eyal and Teichman, Doron (2018) Behavioral Law and Economics - Introduction. Oxford University Press, 2018.

Zúñiga, Nieves (2018) "Behavioural Changes Against Corruption”, U4 Anti-Corruption Resource Centre, U4 Helpdesk Answer, n.8: 1-12 